\title{
Unexplored olive cultivars from the Valencian Community (Spain): some chemical characteristics as a valorization strategy
}

\author{
Domingo C. Salazar-García ${ }^{1} \cdot$ Ricardo Malheiro ${ }^{2,3} \cdot$ José Alberto Pereira ${ }^{4} \cdot$ Isabel Lopéz-Cortés $^{5}$
}

Received: 27 August 2018 / Accepted: 8 September 2018 / Published online: 28 September 2018

(c) Springer-Verlag GmbH Germany, part of Springer Nature 2018

\begin{abstract}
The olive processing industry has till date been dominated by a small group of cultivars, leading to the possibility of some olive cultivars becoming extinct in the near future. In this study, we determined the composition of some chemical components in the olive oils from 31 minor olive cultivars of the Valencian Community. Our main aim was to identify suitable cultivars, which could produce differentiated olive oils, thus aiming towards their valorization. The average oil content of minor olive cultivars was found to be good, with some of them reporting approximately $60 \%$ (dry basis). On average, the total phenolic content was $229 \mathrm{mg} \mathrm{kg}^{-1}$, with cv. Mas Blanc reporting the highest content $\left(570 \mathrm{mg} \mathrm{kg}^{-1}\right)$. Among the various tocopherols found in olives, $\alpha$-tocopherol was the main constituent, with a maximum concentration of $290.6 \mathrm{mg} \mathrm{kg}^{-1}$. Linoleic acid was the main polyunsaturated fatty acid and varied between $3.4 \%$ (cv. Del Pomet) and 16.9\% (cv. Blanqueta Enguera). Special attention needs to be paid to the composition of sterols, since some olive oils exceeded the limits established for some sterols by the current European legislation. Some of the cultivars studied were highly productive, and originated differentiated olive oils with a rich composition of antioxidants and essential fatty acids. In some cases, these beneficial compounds were higher than those of commercial oils obtained from the most common cultivars worldwide. These results could contribute to the commercial exploitation of some of the studied cultivars.
\end{abstract}

Keywords Minor cultivars valorization · Olea europaea L. · Olive oil · Characterization · Legislation · Cultivar discrimination

Ricardo Malheiro

rmalheiro@ipb.pt

$\triangle$ Isabel Lopéz-Cortés

islocor@upv.es

1 Foundation for Science, Grupo de Investigación en Prehistoria IT-622-13 (UPV-EHV) IKERBASQUE-Basque, Vitoria, Spain

2 Centro de Investigação de Montanha (CIMO), ESA, Instituto Politécnico de Bragança, Campus Santa Apolónia, 5300-253 Bragança, Portugal

3 REQUIMTE-LAQV/Laboratório de Bromatologia e Hidrologia, Faculdade de Farmácia, Universidade do Porto, Porto, Portugal

4 Escola Superior Agrária, Instituto Politécnico de Bragança, Campus Santa Apolónia, Bragança, Portugal

5 Departamento Producción Vegetal, Universitat Politècnica de València, Camino de Vera s/n, 46022 Valencia, Spain

\section{Introduction}

The cultivation of olives has increased tremendously in the last decades as a consequence of the increased demand for olive oil and table olives among consumers. Because of the advances in agronomic practices, the yield of Olea europaea L. was rampant in recent times. In modern olive groves, like super intensive or hedgerow olive orchards, some olive cultivars have not been able to adapt to this type of cultivation. To ensure the intensive growth of olives, good cultivars are needed: cvs. Arbequina and Arbosana (the Spanish cultivars), cv. Leccino (the Italian cultivar), cv. Koroneiki (the Greek cultivar) are some of the prominent examples; they have been specifically developed to adapt to these cultivation conditions [1]. Several ancient and traditional olive cultivars cannot be grown in new olive orchards as they fail to proliferate in these cultivation conditions. In many other parts of the world, farmers have removed the old trees in traditional/ low density olive orchards. New foreign olive cultivars 
have been planted in these orchards because they are more productive and profitable in terms of yield. Consequently, the traditional and minor olive cultivars have almost vanished from olive orchards in several regions in the world. In Spain, about 262 cultivars were identified and classified into four main groups: major, secondary, dispersed, and local. Among the 262 cultivars, there were only 24 major cultivars [2]. At the beginning of the twenty-first century, cvs. Picual, Arbequina and Hojiblanca [3] were the only cultivars grown in more than $90 \%$ of new olive orchards in Spain. Due to the massive cultivation of these cultivars, olive germplasm was significantly reduced. The cv. Arbequina is one of the most representative olive cultivars in Spain and in other parts of the world. In fact, it is grown in almost all olive producing countries [4]. However, several traditional olive cultivars are considered local, dispersed, secondary, or minor olive cultivars. These olive cultivars have the potential to be widespread based on their productivity: the quality and chemical composition of the olive products from these cultivars is usually taken into account for growing them on a large scale. In recent years, researchers have performed chemical characterizations of these minor olive cultivars. These researchers wanted to use this information to valorize them in Tunisia [5], Greece [6], Spain [7], and around the world [8]. In the Valencian Community (Spain), recent studies were conducted to determine the quality parameters and some components of olive oil from 45 olive cultivars [9]. According to Ruiz-Domínguez et al., "a greater diversity exists in the economically less important varieties, indicating that selection among them for specific composition profiles with desirable properties... can be of interest for the recovery of neglected varieties" [9]. In the present study, we emphasized the characterization of minor cultivars. Moreover, the potentialities of this information were also explored in this study.

Apart from their quality, the minor composition of olive oils plays an important role in the overall properties of the final product. Therefore, the determination of minor components such as sterols, tocopherols and phenolic compounds, as well as of fatty acids is imperative to assess the potentialities of olive oils [10].

The main aim of the present work is to contribute to the literature of minor olive cultivars. In this study, we assessed whether minor olive cultivars could be used as important assets in olive production for the creation of differentiated olive oils. Therefore, the fat content concerning different olive cultivars was determined, and we also determined some chemical components (fatty acids, sterols, $\alpha$-tocopherol, and total phenols content) of 31 minor olive cultivars from the Valencian Community. The sole purpose of the analyses was to valorize these minor cultivars and promote their cultivation.

\section{Materials and methods}

\section{Plant material collection}

In the present study, minor olive cultivars were obtained from the Valencian Community in Spain to chemically characterize their olive oils. In order to identify the olive cultivars, we used the system established by the International Union for the Protection of New Varieties of Plants (UPOV guidelines TG/99/4). After identifying all the cultivars, we compared them with standard cultivars present in the collection fields of the Universitat Politècnica de València. From all the collected material, some olive cultivars were selected. The selected cultivars were included in the collection for future research and for comparisons of the agronomic behavior. In total, 31 olive cultivars were selected: cvs. Aguilar, Blanqueta Enguera, Borriolenca, Cabaret, Callosina, Carrasqueña, Cuquillo, Changlot Real, Del Patró, Del Pomet, Figuereta, Genovesa, Gileta, Grossal, Lloma, Llumero, Marfil, Mas Blanc, Millareja, Monteaguda, Morons, Morruda, Negra, Piñonera, Romana, Rotja, Rufina, Seniero, Valentins, Vallesa, and Vera. Olives from the 31 cultivars were collected throughout the Valencian Community. As shown in Fig. 1, the olives were collected in 11 municipalities. All olives were allowed to grow till they reached their optimal ripening stage, a maturation index of $2-3$, according to the procedure proposed by Hermoso et al. [11]. Approximately $10 \mathrm{~kg}$ of olives were handpicked from each cultivar; then, they were immediately transported to the laboratory.

\section{Olive oils extraction, moisture, and oil content determination}

After harvesting the olives, the olive oil was extracted within the first $24 \mathrm{~h}$. The extraction was carried out by following the methodology described by Malheiro et al. [12]: olive oils were extracted in an Abencor analyzer (Comercial Abengoa S.A., Seville, Spain) with three main units: a mill, a thermobeater (malaxation of olive pastes under controlled temperature conditions), and a centrifuge. Olive samples ( $n=5$ per cultivar) were milled with a hammer miller, and the resultant olive paste was homogenized. About $700 \mathrm{~g}$ of olive paste was transferred to the thermobeater unit, where malaxation was carried out for $30 \mathrm{~min}$ in a thermostatic water bath at $25{ }^{\circ} \mathrm{C}$. In the final $5 \mathrm{~min}$ of each malaxation, $100 \mathrm{~mL}$ of water at $35{ }^{\circ} \mathrm{C}$ was added to improve the extraction of olive oil. In the centrifugation unit, the mixture was centrifuged for $1 \mathrm{~min}$ at $3500 \mathrm{rpm}$ and decanted. The olive oil was collected and stored in 100-mL dark bottles.

In order to determine the fat content in the olive paste, the oil was extracted from the paste in a Soxtec Avanti 


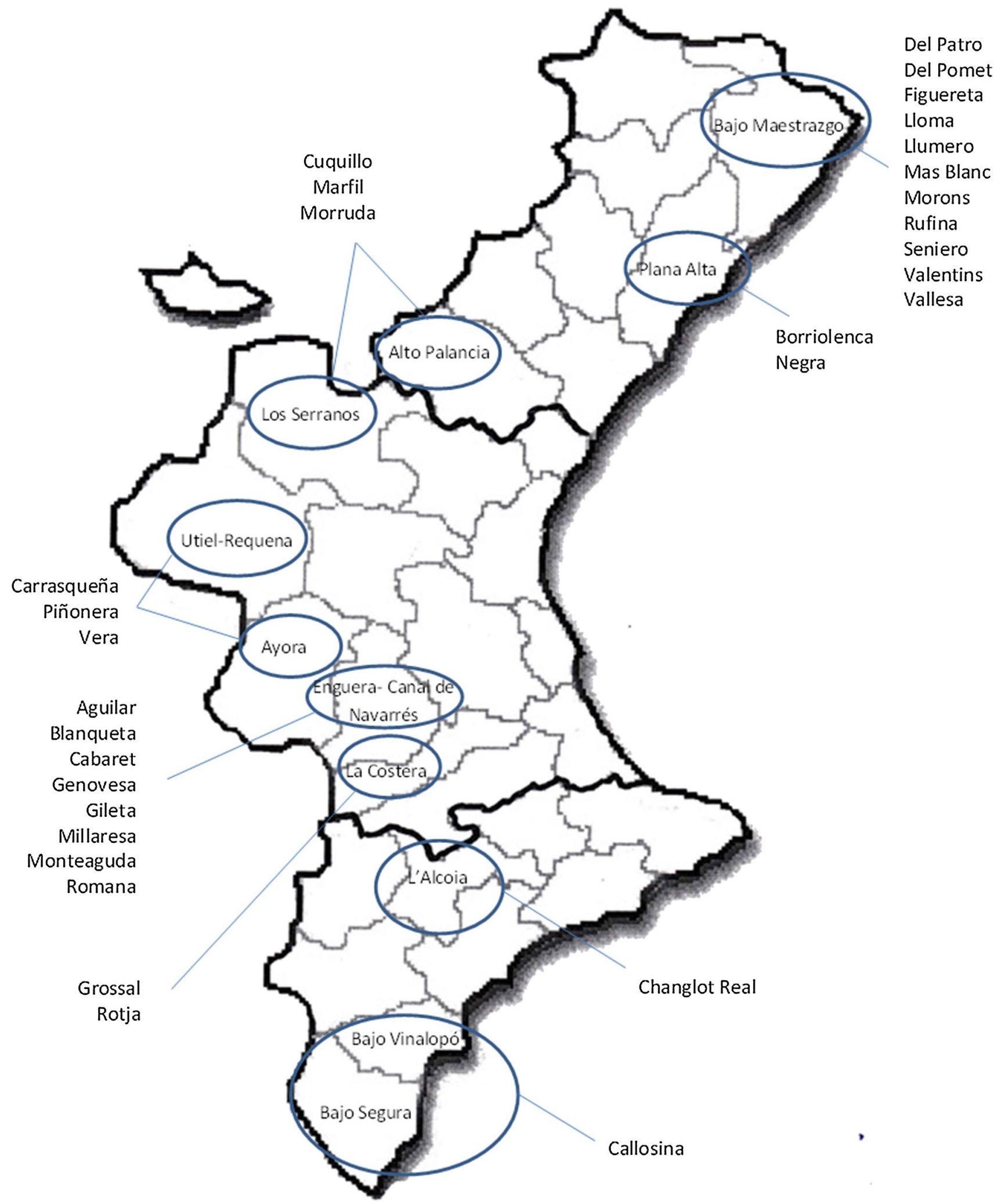

Fig. 1 Location of 31 minor olive cultivars from the Valencia Community (Spain) 
2050 automatic extraction system (Foss Tecator, Höganäs, Sweden). The extraction was carried out by following the procedure described in the Annex XV of the Commission Regulation No. 2568/91 and further amendments [13]. Moisture content was determined by desiccation at $105{ }^{\circ} \mathrm{C}$ for $24 \mathrm{~h}$.

\section{Fatty acids determination}

The fatty acids profile was determined by following the standard UNE55,037-73. The samples were analyzed in a GC 8000Top (CE Instruments Ltd.), which was equipped with a flame ionization detector (FID); the samples were injected into a Supelcowax 10 column $(30 \mathrm{~mm} \times 0.25 \mathrm{~mm})$ (Sigma-Aldrich). Helium was the carrier gas at a flow of $1 \mathrm{~mL} / \mathrm{min}$. The temperatures of the injector and detector were fixed at $250{ }^{\circ} \mathrm{C}$ and $270{ }^{\circ} \mathrm{C}$, respectively; an injection volume of $1 \mu \mathrm{L}$ was used for sample analysis. The oven temperature was programmed at $120^{\circ} \mathrm{C}$ during the first $3 \mathrm{~min}$ with an increase of $4{ }^{\circ} \mathrm{C} / \mathrm{min}$ until $220^{\circ} \mathrm{C}$. The relative percentage of each fatty acid was determined by conducting an internal normalization of the chromatographic peak areas. A standard mixture of fatty acids methyl esters (Supelco37 FAME Mix) was used for identification and calibration purposes.

\section{Sterols and tocopherols determination}

In order to analyze sterols and tocopherols, we used $100 \mathrm{mg}$ of fat with a known weight of an internal standard (5,7-dimethyltocol), prepared following the technique developed by Slover et al. [14]. Saponification was performed with aqueous potassium hydroxide. The unsaponifiable fraction was extracted with cyclohexane and the solvent was removed with a stream of nitrogen The derivatization was performed with bis(trimethylsilyl)-trifluoroacetamide plus $1 \%$ of trimethylchlorosilane with pyridine [14]. The derivatized total unsaponifiable fraction was injected in the same equipment used for fatty acids analysis; the analyses were carried out in a Tracer TR Sterol column $(30 \mathrm{~m} \times 0.22 \mathrm{~mm}$; Teknokroma, Spain). The temperatures of the injector and detector were fixed at $290{ }^{\circ} \mathrm{C}$ and $300{ }^{\circ} \mathrm{C}$, respectively. The oven temperature was maintained at $265^{\circ} \mathrm{C}$, and a sample volume of $1 \mu \mathrm{L}$ was injected into the equipment.

\section{Total phenolic content determination}

The procedure was carried out using the analytical methodology described by Sousa et al. [15]; however, slight modifications were introduced in the procedure. Briefly, $2.5 \mathrm{~g}$ of olive oil were diluted $(1: 1 \mathrm{w} / \mathrm{v})$ with $n$-hexane; the oil was extracted thrice with $2.5 \mathrm{~mL}$ of methanol/water (80:20; v/v). The mixture was centrifuged for $5 \mathrm{~min}$ at $5000 \mathrm{rpm}$. From the combined extract, $1 \mathrm{~mL}$ was added to the same amount of Folin-Ciocalteu reagent and $\mathrm{Na}_{2} \mathrm{CO}_{3}(7.5 \%)$. Then, $7 \mathrm{~mL}$ of purified water was added to this solution mixture. After homogenization, the solution mixture was stored overnight. Finally, a spectrophotometric analysis was performed at $\lambda=765 \mathrm{~nm}$.

For quantification purposes, a calibration curve of caffeic acid in methanol was prepared in the concentration range of $0.04-0.18 \mathrm{mg} / \mathrm{mL}$. The final results were expressed as $\mathrm{mg}$ of caffeic acid equivalents per $\mathrm{kg}$ of olive oil (mg CAE $/ \mathrm{kg}$ ).

\section{Statistical analysis}

An analysis of variance (ANOVA), a principal component analysis (PCA), and a linear discriminant analysis (LDA) were carried out according to the procedure described by Limón et al. [16]. Statistical analyses were performed using SPSS software, version 22.0 (IBM Corporation, New York, USA).

\section{Results and discussion}

\section{Oil content}

Figure $2 \mathrm{a}, \mathrm{b}$ presents the results of the oil content obtained in both fresh and dry weight of olives, respectively. The results differed significantly for all the 31 olive cultivars $(p<0.001)$. In fresh weight, the values varied between $19.2 \%$ (cv. Del Pomet) and 25.8\% (cv. Romana) (Fig. 2a). In some cases, our results were comparable to those obtained by RuizDomínguez et al. [9] as fresh weight values varied between 7.6 and $23.8 \%$. In terms of dry weight, cv. Del Pomet showed a significantly lower content of $40.1 \%$, while cv. Millareja reported the highest value of $59.4 \%$ of dry weight (Fig. 2b). The results indicate that some minor cultivars have high oil content, including cvs. Millareja (59.4\%), Seniero (57.8\%), and Monteaguda (57.0\%). Compared to Spanish and worldwide important olive cultivars, higher values were reported: cv. Arbequina (53.4\% d.w. at harvest moment) [17]; and cv. Coratina (20.5\%) [18]. The oil content of cv. Romana was quite similar to those reported for cv. Koroneiki cultivated in Tunisia (25.4\%) [19]. Therefore, the minor olive cultivars of Valencia have high oil content despite being produced in traditional olive orchards; consequently, these minor olive cultivars should be considered in new olive orchards. For these results to be validated, we should compare these minor cultivars with standard and reference olive cultivars. It is important to note that standard and reference olive cultivars must be grown in the same agroclimatic conditions. Furthermore, they should also be harvested at the same ripening stage, and must follow the same agricultural practices and processing techniques. 
Fig. 2 Oil yield (a \% in fresh weight; and $\mathbf{b} \%$ in dry weight) of the 31 minor olive cultivars from Valencia Community ( $\mathrm{a}-1$ mean values with different letters differ significantly, $p<0.05$ )
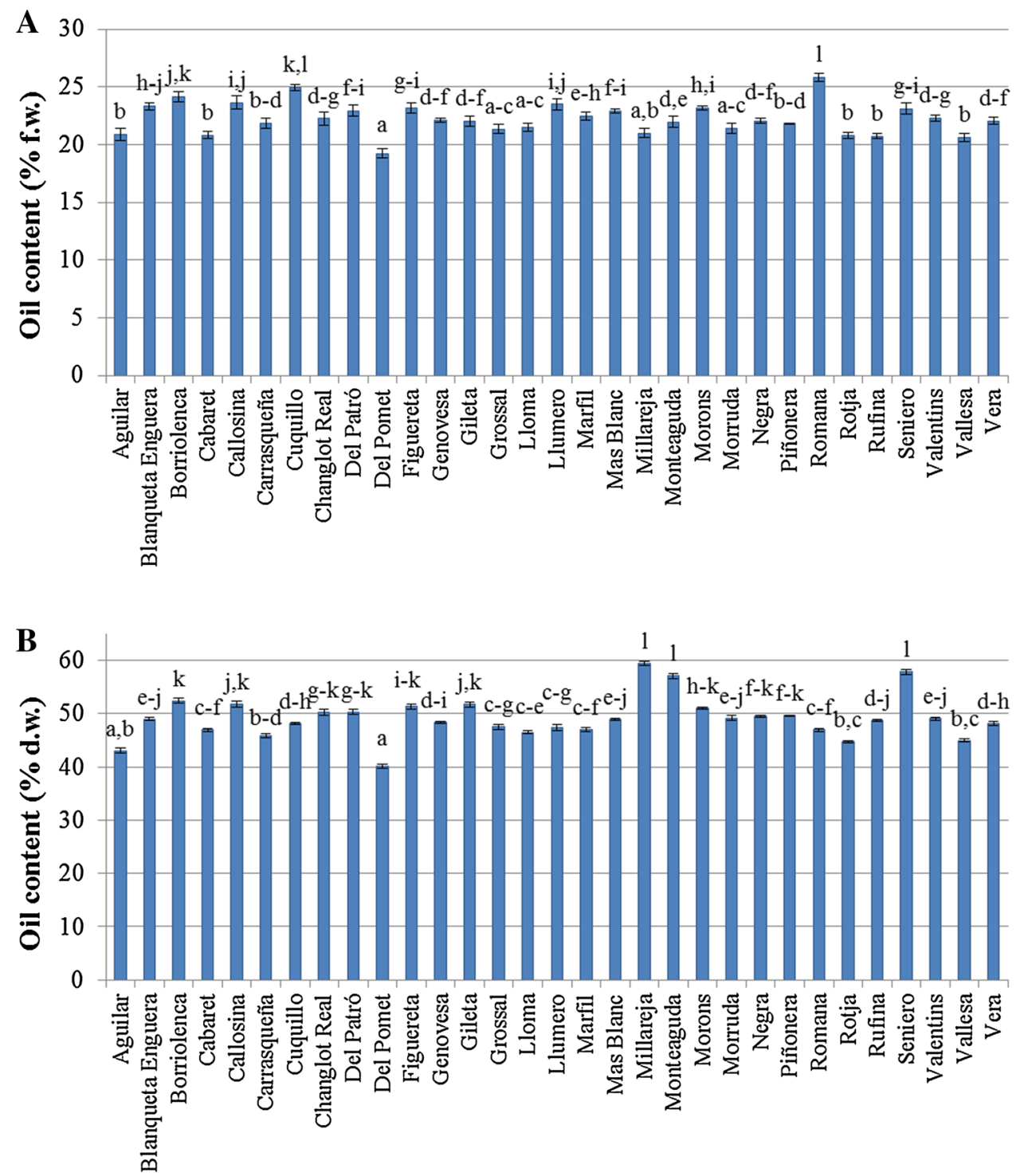

\section{Fatty acids composition}

Table 1 presents the fatty acid profile of the 31 olive cultivars. As expected, oleic acid $\left(\mathrm{C}_{18: 1}\right)$ was the most abundant fatty acid. Ranging from $62.0 \%$ (cv. Blanqueta Enguera) to $84.0 \%$ (cv. Carrasqueña), the content of oleic acid varied significantly among the 31 cultivars $(p<0.001)$. Oleic acid was followed by palmitic acid $\left(\mathrm{C}_{16: 0}\right)$ whose proportion varied between $7.69 \%$ (cv. Lloma) and 18.6\% (cv. Blanqueta Enguera) among the 31 different cultivars. The third most abundant fatty acid was linoleic acid $\left(\mathrm{C}_{18: 2}\right)$. This fatty acid, together with linolenic acid $\left(\mathrm{C}_{18: 3}\right)$, is very important because they are both essential fatty acids [20]. Humans cannot synthesize these fatty acids naturally; however, they are essential to health and must be included in our diet. The proportion of linoleic acid varied from 3.43\% (cv. Del Pomet) to $16.9 \%$ (cv. Blanqueta Enguera) among the 31 cultivars included in this study. Furthermore, cv. Blanqueta Enguera was a good source of polyunsaturated fatty acids (PUFA) as it contained $17.5 \%$ of PUFA. Since PUFA content is higher in cv. Blanqueta Enguera, the stability of the oil extracted will be affected to some extent. This is because PUFA are the main substrates in the autoxidation process, which leads to the chemical deterioration of the oil. If olive oils are extracted from cv. Blanqueta Enguera, then they must be consumed immediately after extraction, as their quality deteriorates due to oxidation if stored for longer periods. Note that it is beneficial to consume this olive oil as it contains good amounts of antioxidants, namely, phenolic compounds, tocopherols, and sterols (Table 2).

Our results are in line with those obtained by RuizDomínguez et al. [9] however, with great discrepancy observed in the results regarding cv. Gileta. For example, we detected lower amounts of PUFA and lower amounts of 


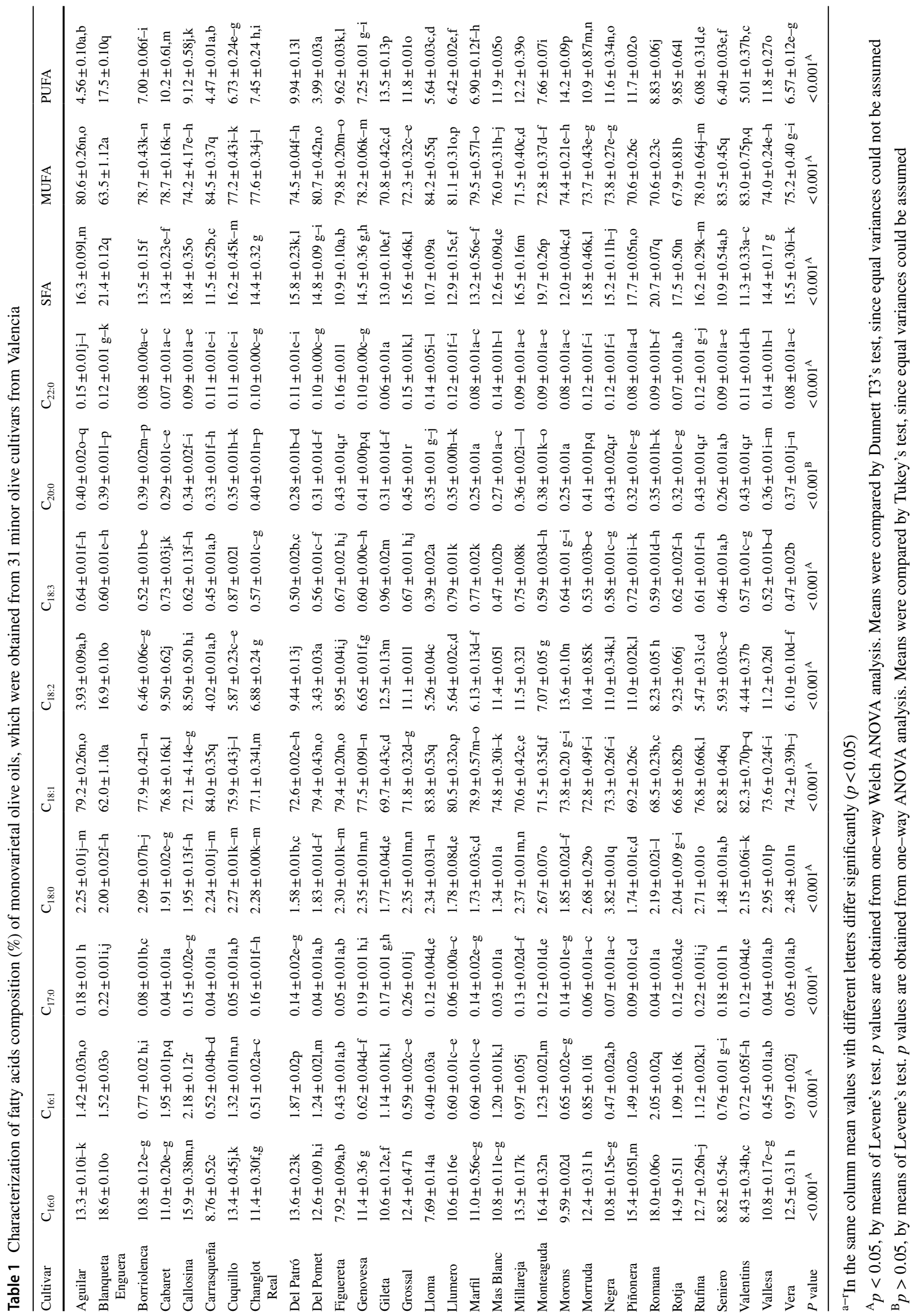


Table 2 Sterols (g $100 \mathrm{~g}^{-1}$ of sterols\%), $\alpha$-tocopherol ( $\mathrm{mg} \mathrm{kg}^{-1}$ of oil), and total phenols content ( $\mathrm{mg} \mathrm{kg}^{-1}$ of oil) of monovarietal olive oils obtained from 31 minor olive cultivars from Valencia

\begin{tabular}{|c|c|c|c|c|c|}
\hline Cultivar & Apparent $\beta$-sitosterol & Campesterol & Stigmasterol & $\alpha$-Tocopherol & Total phenols content \\
\hline Aguilar & $95.0 \pm 0.14 \mathrm{~d}-\mathrm{j}$ & $3.1 \pm 0.02 \mathrm{~d}-\mathrm{f}$ & $1.6 \pm 0.40 \mathrm{i}$ & $139.2 \pm 0.91 \mathrm{~d}$ & $170 \pm 1.17 \mathrm{k}$ \\
\hline Blanqueta Enguera & $94.2 \pm 0.12 b-\mathrm{e}$ & $4.3 \pm 0.05 \mathrm{k}$ & $0.6 \pm 0.08 \mathrm{a}-\mathrm{c}$ & $171.6 \pm 1.50 \mathrm{~h}-\mathrm{j}$ & $321 \pm 1.19 \mathrm{t}$ \\
\hline Borriolenca & $91.5 \pm 0.44 \mathrm{a}$ & $4.3 \pm 0.06 \mathrm{k}$ & $1.4 \pm 1.23 \mathrm{f}-\mathrm{i}$ & $61.0 \pm 0.15 \mathrm{a}$ & $121 \pm 1.44 b$ \\
\hline Cabaret & $93.7 \pm 0.10 b, c$ & $3.8 \pm 0.04 \mathrm{i}, \mathrm{j}$ & $0.4 \pm 0.01 \mathrm{a}$ & $198.3 \pm 0.83 \mathrm{~m}$ & $296 \pm 0.349 q$ \\
\hline Callosina & $95.8 \pm 0.21 \mathrm{i}-1$ & $2.7 \pm 0.26 \mathrm{a}-\mathrm{c}$ & $0.4 \pm 0.01 \mathrm{a}$ & $255.3 \pm 2.93 \mathrm{o}$ & $151 \pm 1.09 \mathrm{~h}$ \\
\hline Carrasqueña & $94.5 \pm 0.73 b-g$ & $3.7 \pm 0.33 \mathrm{~h}-\mathrm{j}$ & $0.7 \pm 0.01 \mathrm{a}-\mathrm{e}$ & $154.2 \pm 0.62 \mathrm{e}-\mathrm{g}$ & $192 \pm 1.50 \mathrm{~m}$ \\
\hline Cuquillo & $96.2 \pm 0.35 \mathrm{k}, 1$ & $3.1 \pm 0.04 c-f$ & $0.7 \pm 0.05 \mathrm{a}-\mathrm{e}$ & $342.9 \pm 0.93 r$ & $200 \pm 1.10 n$ \\
\hline Changlot Real & $95.4 \pm 0.61 \mathrm{f}-1$ & $2.8 \pm 0.05 b-d$ & $1.2 \pm 0.04 \mathrm{~d}-\mathrm{i}$ & $186.2 \pm 2.11 \mathrm{k}-\mathrm{m}$ & $201 \pm 0.857 \mathrm{n}$ \\
\hline Del Patró & $94.6 \pm 0.19 c-h$ & $3.9 \pm 0.02 \mathrm{j}$ & $1.5 \pm 0.06 \mathrm{~g}-\mathrm{i}$ & $113.9 \pm 0.24 \mathrm{c}$ & $122 \pm 0.210 \mathrm{~b}, \mathrm{c}$ \\
\hline Del Pomet & $94.7 \pm 0.42 \mathrm{c}-\mathrm{i}$ & $2.6 \pm 0.03 \mathrm{a}, \mathrm{b}$ & $1.4 \pm 0.03 \mathrm{f}-\mathrm{i}$ & $98.3 \pm 0.24 b$ & $126 \pm 0.330 \mathrm{~d}$ \\
\hline Figuereta & $95.5 \pm 0.12 \mathrm{~g}-1$ & $3.2 \pm 0.02 \mathrm{e}-\mathrm{g}$ & $1.3 \pm 0.24 \mathrm{e}-\mathrm{i}$ & $161.8 \pm 0.58 \mathrm{~g}, \mathrm{~h}$ & $184 \pm 0.1671$ \\
\hline Genovesa & $93.6 \pm 0.11 b, c$ & $3.5 \pm 0.27 \mathrm{~g}-\mathrm{i}$ & $1.7 \pm 0.14 \mathrm{i}$ & $70.7 \pm 0.33 \mathrm{a}$ & $141 \pm 0.812 \mathrm{f}$ \\
\hline Gileta & $94.6 \pm 0.35 \mathrm{c}-\mathrm{h}$ & $3.3 \pm 0.04 \mathrm{e}-\mathrm{g}$ & $1.5 \pm 0.02 \mathrm{~h}, \mathrm{i}$ & $114.9 \pm 0.27 \mathrm{c}$ & $344 \pm 0.171 \mathrm{v}$ \\
\hline Grossal & $95.0 \pm 0.63 \mathrm{~d}-\mathrm{j}$ & $3.4 \pm 0.16 \mathrm{f}-\mathrm{h}$ & $1.4 \pm 0.12 \mathrm{f}-\mathrm{i}$ & $130.9 \pm 0.96 \mathrm{~d}$ & $301 \pm 0.558 \mathrm{~s}$ \\
\hline Lloma & $93.7 \pm 0.76 b, c$ & $3.8 \pm 0.05 i, j$ & $1.1 \pm 0.04 \mathrm{~b}-\mathrm{i}$ & $183.9 \pm 0.49 \mathrm{j}-1$ & $123 \pm 0.436 c$ \\
\hline Llumero & $94.3 \pm 0.64 b-\mathrm{f}$ & $3.8 \pm 0.29 \mathrm{i}, \mathrm{j}$ & $0.6 \pm 0.03 \mathrm{a}-\mathrm{c}$ & $141.9 \pm 2.85 \mathrm{~d}-\mathrm{f}$ & $131 \pm 0.885 \mathrm{e}$ \\
\hline Marfil & $96.2 \pm 0.35 \mathrm{k}, 1$ & $3.0 \pm 0.01 \mathrm{c}-\mathrm{e}$ & $0.5 \pm 0.01 \mathrm{a}$ & $271.0 \pm 0.67 \mathrm{p}$ & $447 \pm 0.192 y$ \\
\hline Mas Blanc & $93.7 \pm 0.59 b-c$ & $2.7 \pm 0.10 \mathrm{a}, \mathrm{b}$ & $0.3 \pm 0.03 \mathrm{a}$ & $187.1 \pm 0.18 \mathrm{~h}-\mathrm{k}$ & $570 \pm 1.18 \mathrm{z}$ \\
\hline Millareja & $93.4 \pm 0.70 b$ & $3.5 \pm 0.06 \mathrm{~g}-\mathrm{j}$ & $0.6 \pm 0.06 \mathrm{a}-\mathrm{d}$ & $180.4 \pm 2.08 \mathrm{i}-1$ & $127 \pm 0.420 \mathrm{~d}$ \\
\hline Monteaguda & $94.4 \pm 0.53 \mathrm{~b}-\mathrm{g}$ & $2.7 \pm 0.05 a-c$ & $0.5 \pm 0.03 a, b$ & $237.7 \pm 1.72 \mathrm{n}$ & $439 \pm 1.72 x$ \\
\hline Morons & $94.0 \pm 0.31 b-d$ & $3.9 \pm 0.06 \mathrm{j}$ & $0.6 \pm 0.04 \mathrm{a}-\mathrm{c}$ & $168.1 \pm 0.29 \mathrm{~g}-\mathrm{i}$ & $168 \pm 0.115 j$ \\
\hline Morruda & $95.7 \pm 0.50 \mathrm{~h}-1$ & $2.8 \pm 0.38 b-d$ & $0.8 \pm 0.14 \mathrm{a}-\mathrm{e}$ & $155.4 \pm 2.01 \mathrm{f}, \mathrm{g}$ & $325 \pm 0.751 u$ \\
\hline Negra & $96.3 \pm 0.371$ & $2.9 \pm 0.02 b-\mathrm{e}$ & $0.6 \pm 0.04 \mathrm{a}-\mathrm{d}$ & $250.4 \pm 0.99 \mathrm{n}, \mathrm{o}$ & $419 \pm 0.161 w$ \\
\hline Piñonera & $95.1 \pm 0.06 \mathrm{e}-\mathrm{k}$ & $3.9 \pm 0.02 \mathrm{j}$ & $0.8 \pm 0.01 \mathrm{a}-\mathrm{g}$ & $65.0 \pm 0.11 \mathrm{a}$ & $190 \pm 0.159 \mathrm{~m}$ \\
\hline Romana & $95.6 \pm 0.06 \mathrm{~g}-1$ & $3.8 \pm 0.02 \mathrm{i}, \mathrm{j}$ & $0.6 \pm 0.06 \mathrm{a}-\mathrm{c}$ & $198.6 \pm 1.85 \mathrm{~m}$ & $99 \pm 0.149 \mathrm{a}$ \\
\hline Rotja & $95.6 \pm 0.25 \mathrm{~h}-1$ & $3.3 \pm 0.07 \mathrm{e}-\mathrm{g}$ & $0.9 \pm 0.06 \mathrm{a}-\mathrm{h}$ & $281.9 \pm 4.50 \mathrm{p}, \mathrm{q}$ & $143 \pm 0.152 \mathrm{~g}$ \\
\hline Rufina & $94.7 \pm 0.41 \mathrm{c}-\mathrm{i}$ & $3.2 \pm 0.03 \mathrm{e}-\mathrm{g}$ & $1.1 \pm 0.03 \mathrm{c}-\mathrm{i}$ & $192.5 \pm 3.241, \mathrm{~m}$ & $299 \pm 0.174 \mathrm{r}$ \\
\hline Seniero & $96.0 \pm 0.84 \mathrm{i}-1$ & $2.8 \pm 0.09 b-d$ & $0.8 \pm 0.05 \mathrm{a}-\mathrm{g}$ & $155.7 \pm 6.08 \mathrm{f}, \mathrm{g}$ & $204 \pm 0.7950$ \\
\hline Valentins & $96.3 \pm 0.25 \mathrm{k}, 1$ & $2.4 \pm 0.15 \mathrm{a}$ & $0.8 \pm 0.11 \mathrm{a}-\mathrm{f}$ & $140.2 \pm 0.88 \mathrm{~d}, \mathrm{e}$ & $154 \pm 0.150 \mathrm{i}$ \\
\hline Vallesa & $91.1 \pm 1.00 \mathrm{a}$ & $4.6 \pm 0.20 \mathrm{k}$ & $1.6 \pm 0.43 \mathrm{i}$ & $61.0 \pm 0.35 \mathrm{a}$ & $130 \pm 0.323 \mathrm{e}$ \\
\hline Vera & $94.7 \pm 0.12 \mathrm{c}-\mathrm{h}$ & $3.0 \pm 0.06 \mathrm{~b}-\mathrm{e}$ & $0.4 \pm 0.11 \mathrm{a}$ & $290.6 \pm 1.23 q$ & $272 \pm 0.232 p$ \\
\hline$p$ value & $<0.001^{\mathrm{A}}$ & $<0.001^{\mathrm{A}}$ & $<0.001^{\mathrm{A}}$ & $<0.001^{\mathrm{A}}$ & $<0.001^{\mathrm{A}}$ \\
\hline
\end{tabular}

${ }^{\mathrm{a}-\mathrm{r}}$ In the same column mean values with different letters differ significantly $(p<0.05)$

${ }^{\text {A }} p<0.05$, by means of Levene's test. $p$ values are obtained from one-way Welch ANOVA analysis. Means were compared by Dunnett T3's test, since equal variances could not be assumed

linoleic acid, $12.5 \%$ in our study against the $22.85 \%$ found by Ruiz-Domínguez et al. [9]. Considering the European legislation [13], the results obtained for myristic $\left(\mathrm{C}_{14: 0}\right)$ (data not shown), linolenic, arachidic $\left(\mathrm{C}_{20: 0}\right)$, eicosanoic $\left(\mathrm{C}_{20: 1}\right)$ (data not shown), behenic $\left(\mathrm{C}_{22: 0}\right)$, and lignoceric acids $\left(\mathrm{C}_{24: 0}\right)$ (data not shown) were below the maximum legal limits in all the cultivars $(\leq 0.03 ; \leq 1.00 ; \leq 0.60$; $\leq$ $0.50 ; \leq 0.20$; and $\leq 0.20$, respectively). Nevertheless, as far as $\mathrm{C}_{14: 0}$ is concerned, other cultivars also report higher values than the legal limits [21].

\section{Sterols and $\boldsymbol{a}$-tocopherol content}

Sterols and tocopherols are beneficial human health [22, 23] by reducing plasma cholesterol [24], and due to their antioxidant properties. Besides, tocopherols also perform important vitaminic functions due to vitamin E [25]. Table 2 shows the amounts of sterols and $\alpha$-tocopherol in the 31 olive oils. The relative percentage of the apparent $\beta$-sitosterol varied between $91.1 \%$ (cv. Vallesa) and 96.3\% (cvs. Negra and Valentins), while campesterol values varied from 2.4 to $4.3 \%$. 
Furthermore, the relative percentage of stigmasterol varied from 0.3 to $1.6 \%$. According to the values established in European legislation [13], the maximum limits of some sterols were exceeded in the olive oils obtained from cvs. Blanqueta Enguera, Borriolenca, and Vallesa. For example, cvs. Borriolenca and Vallesa have less than $93 \%$ of apparent $\beta$-sitosterol. The levels of campesterol were higher than $4 \%$ in the two aforementioned cultivars and in cv. Blanqueta Enguera, thereby exceeding the maximum limits laid down by the European legislation [13]. Nevertheless, we need to highlight that the levels reported for sterols were not obtained by the official method from Regulation (EEC) No. 2568/91 and further amendments [13]. In this sense, the results obtained are indicative and the comparison with the European legislation is not straightforward.

The levels of $\alpha$-tocopherol, varied from $61 \mathrm{mg} \mathrm{kg}^{-1}$ (cvs. Borriolenca and Vallesa) to $343 \mathrm{mg} \mathrm{kg}^{-1}$ (cv. Cuquillo). For similar maturation indexes, cv. Cuquillo reported higher tocopherols content than seven important olive cultivars from Southern Spain (cvs. Arbequina, Carrasqueña, Corniche, Manzanilla Cacereña, Morisca, Picual, and Verdial de Badajoz). In fact, some of these olive cultivars are widely distributed in the world [26]; however, these cultivars were not grown under the same agroclimatic conditions and they were not even treated with the same agricultural and processing techniques. It is important to note that $\alpha$-tocopherol accounts for $11 \%$ of the total oxidative stability of the oil [27].

\section{Total phenols content}

Phenolic compounds are an important component of olive oil because of the following factors: antioxidant properties and health benefits [28]; improvement of the oxidative stability [27, 29]; and enhancement of the olive oil sensory attributes [30]. In the olive oils extracted from the 31 minor cultivars of the Valencian Community, the average total phenols content was $229 \mathrm{mg} \mathrm{kg}^{-1}$ (Table 2). However, the phenolic contents ranged from $99 \mathrm{mg} \mathrm{kg}^{-1}$ (cv. Romana) to $570 \mathrm{mg} \mathrm{kg}^{-1}$ (cv. Mas Blanc) (Table 2). Ruiz-Domínguez et al. [9] reported similar results for the total amount of phenols: the amount of total phenols varied between 55 and $646 \mathrm{mg} \mathrm{kg}^{-1}$, with an average value of $243 \mathrm{mg} \mathrm{kg}^{-1}$. In four of the olive cultivars under study [cvs. Negra (419 mg $\mathrm{kg}^{-1}$ ), Monteaguda (439 $\mathrm{mg} \mathrm{kg}^{-1}$ ), Marfil (447 $\mathrm{mg} \mathrm{kg}^{-1}$ ), and Mas Blanc $\left(570 \mathrm{mg} \mathrm{kg}^{-1}\right)$ ], an appreciable amount of phenols was detected $\left(>400 \mathrm{mg} \mathrm{kg}^{-1}\right)$. The amount of phenolic compounds mainly depends on the following factors: olive cultivar [31], cultivation system, agricultural practices, region of cultivation [32], and maturation stage [33, 34]. In the 31 olive cultivars, the amount of phenolic compounds varied because of the aforementioned factors or due to a conjunction of some of those factors. Besides the variation in the phenolic content of some of the studied cultivars, it should be emphasized that some of these cultivars may become extinct in the near future. Nevertheless, the phenolic content of some of these cultivars is greater than that observed in cv. Arbequina, which is one of the most common olive cultivars in Spain and in other parts of the world [35, 36]. For comparative purposes, note that these cultivars were grown under different agroclimatic conditions and they were treated with different agricultural and processing techniques; therefore, the comparison is just indicative. These olive oils are a good source of natural phenolic compounds, which enhances the olive oil sensory and bioactive properties, and consequently improves the olive oil shelf-life.

\section{Differentiation and discrimination of olive cultivars}

After determining the chemical compositions (fatty acids, $\alpha$-tocopherol, total phenols content, and sterols) and the oil content of 31 monovarietal olive oils, we tried to distinguish and discriminate these oils by performing PCA and LDA. As shown in Figs. 3 and 4, these 31 olive cultivars could be differentiated and distinguished on the basis of their chemical composition and oil content, respectively. For example, cvs. Marfil, Mas Blanc, and Monteaguda were characterized by their higher phenol content, $\alpha$-tocopherol, and apparent $\beta$-sitosterol. These three groups of components influence the olive oil properties. This is because all these compounds have significant antioxidant properties. Therefore, olive oils extracted from these cultivars might have higher

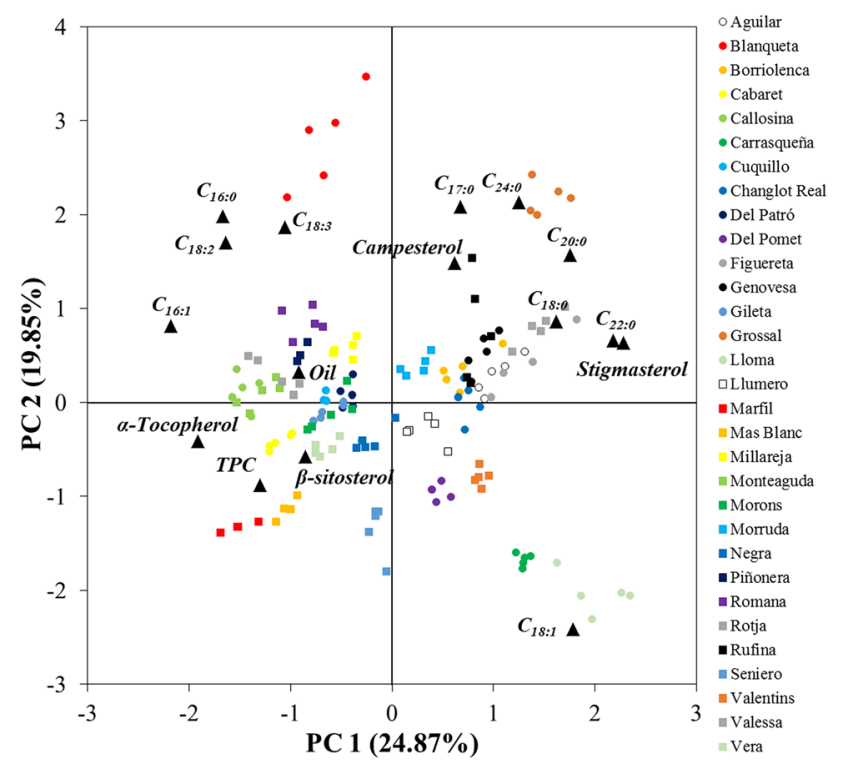

Fig. 3 Principal component analysis obtained by using the fatty acids profile, sterols, $\alpha$-tocopherol, total phenols content and oil yield of the 31 minor olive cultivars from Valencia. The two principal components accounted for $44.72 \%$ of the total variance of the data 


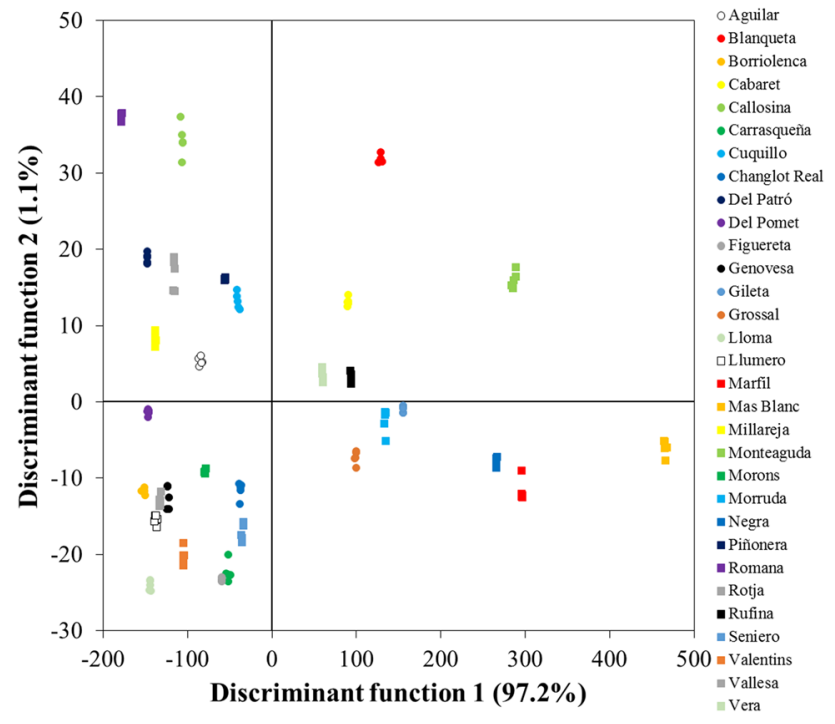

Fig. 4 Linear discriminant analysis obtained from the chemical composition of the 31 olive oils from Valencia Community. The discriminant functions accounted for $98.3 \%$ of the total variance

stability than those extracted from other cultivars, with lower amounts of these components [27]. Furthermore, these olive oils have many health benefits due to their antioxidant content. Therefore, consumers are advised to include these olive oils in their diet and avail the health benefits of antioxidants [37]. A discriminate model was developed by performing stepwise LDA, where the first two discriminant functions were associated with $98.3 \%$ of the variance of experimental data (Fig. 4). A very satisfactory performance was observed in the built model: it correctly assigned all the 31 olive oils with the original groups. In addition, it was also suitable for the cross-validation procedure (sensitivities and sensibilities of $100 \%$ ). Other authors were also able to identify olive oil samples by performing LDA. In order to confirm the identity of olive oil samples, they also performed a characterization of the chemical components [9, 38-40]. This means that chemical composition can be a useful tool for the identification and differentiation of olive oil cultivars. Furthermore, the differences found among cultivars could improve the olive germplasm by increasing their diversity. This aspect may be crucial in the future, mainly in a clime change scenario, where many olive cultivars may not adapt and may reduce their production considerably, or simply perish. Concerning pests and diseases, the cultivation and introduction of minor cultivars is a good strategy to control their incidence, since some of these cultivars may be less susceptible, and some of them possibly resistant to pathogens and insect pests. Therefore, the inclusion of minor cultivars for the production of olive products may be a pool of genetic resources with advantages not only for the consumer but also regarding a series of ecological-environmental features.

\section{Conclusions}

Based on the results of the present work, the following conclusions were reached: some minor olive cultivars are suitable for producing differentiated olive oils; therefore, some of these cultivars should be cultivated on a commercial scale. The oil content (>50\% dry weight) was high for some of these cultivars, such as cvs. Milareja, Monteaguda, and Seniero. In other cultivars, significant amounts of antioxidant molecules were detected. These molecules certainly increased the value of the olive oil. The antioxidant content was the highest in the following cultivars: Marfil, Mas Blanc, and Monteaguda. In terms of sterol composition, the limits of some cultivars were greater than those established by the European legislation. This was especially pronounced for the following cultivars: Blanqueta Enguera, Borriolenca, and Vallesa. Currently, the same typical olive cultivars are planted in most orchards all over the world. By valorizing these cultivars, we can prevent their complete disappearance.

\section{Compliance with ethical standards}

Conflict of interest All authors declare that we have no conflict of interest, and the article is approved by all authors for publication. I would like to declare on behalf of my co-authors that the work described was original research that has not been published previously, and not under consideration for publication elsewhere, in whole or in part.

Compliance with Ethics requirements This article does not contain any studies with human or animal subjects.

\section{References}

1. Avidan B, Birger R, Abed-El-Hadi F, Salmon O, Hekster O, Friedman Y, Lavee S (2011) Adopting vigorous olive cultivars to high density hedgerow cultivation by soil applications of uniconazole, a gibberellin synthesis inhibitor. Span J Agric Res 9:821-830

2. Barranco D, Rallo L (2000) Olive cultivars in Spain. HortTechnology 10:107-110

3. Navero DB (2000) World catalogue of olive varieties. International Olive Oil Council, Madrid

4. Borges TH, Pereira JA, Cabrera-Vique C, Lara L, Oliveira AF, Seiquer I (2017) Characterization of Arbequina virgin olive oils produced in different regions of Brazil and Spain: physicochemical properties, oxidative stability and fatty acid profile. Food Chem 215:454-462

5. Laroussi-Mezghani S, Le Dréau Y, Molinet J, Hammami M, GratiKamoun N, Artaud J (2016) Biodiversity of Tunisian virgin olive oils: varietal origin classification according to their minor compounds. Eur Food Res Technol 242:1087-1099

6. Kosma I, Vavoura M, Kontakos S, Karabagias I, Kontominas M, Apostolos K, Badeka A (2016) Characterization and classification of extra virgin olive oil from five less well-known Greek olive cultivars. J Am Oil Chem Soc 93:837-848

7. Reboredo-Rodríguez P, González-Barreiro C, Cancho-Grande B, Valli E, Bendini A, Toschi TG, Simal-Gandara J (2016) 
Characterization of virgin olive oils produced with autochthonous Galician varieties. Food Chem 212:162-171

8. Kyçyk O, Aguillera MP, Gaforio JJ, Jiménez A, Beltrán G (2016) Sterol composition of virgin olive oil of forty-three olive cultivars from the World Collection Olive Germplasm Bank of Cordoba. J Sci Food Agric 96:4143-4150

9. Ruiz-Domínguez ML, Raigón MD, Prohens J (2013) Diversity for olive oil composition in a collection of varieties from the region of Valencia (Spain). Food Res Int 54:1941-1949

10. Mateos R, Dominguez MM, Espartero JL, Cert A (2003) Antioxidant effect of phenolic compounds, $\alpha$-tocopherol, and other minor components in virgin olive oil. J Agric Food Chem 51:7170-7175

11. Hermoso M, Uceda M, García A, Morales B, Frias ML, Fernández A (1991) Elaboración de Aceite de Calidad. Consejeria de Agricultura y Pesca, Sevilla

12. Malheiro R, Rodrigues N, Bissaro C, Leimann F, Casal S, Ramalhosa E, Pereira JA (2017) Improvement of sensorial and volatile profiles of olive oil by addition of olive leaves. Eur J Lipid Sci Technol 119:1700177

13. Commission Delegated Regulation (EU) 2016/2095 amending Regulation (EEC) No 2568/91 on the characteristics of olive oil and olive-residue oil and on the relevant methods of analysis. Off J Eur Union L:326

14. Slover HT, Thompson RH, Merola GV (1983) Tocopherol and sterol determination by capillary gas chromatography. J Am Oil Chem Soc 60:1524-1528

15. Sousa A, Casal S, Malheiro R, Lamas H, Bento A, Pereira JA (2015) Aromatized olive oil: Influence of flavouring in quality, composition, stability, antioxidants, and antiradical potential. LWT Food Sci Technol 60:22-28

16. Limón P, Malheiro R, Casal S, Acién-Fernández FG, FernándezSevilla JM, Rodrigues N, Cruz R, Bermejo R, Pereira JA (2015) Improvement of stability and carotenoids fraction of virgin olive oil by addition of microalgae Scenedesmus almeriensis extracts. Food Chem 175:203-211

17. Motilva MJ, Tovar MJ, Romero MP, Alegre S, Girona J (2000) Influence of regulated deficit irrigation strategies applied to olive trees (Arbequina cultivar) on oil yield and oil composition during the fruit ripening period. J Sci Food Agric 80:2037-2043

18. Palese AM, Nuzzo V, Favati F, Pietrafesa A, Celano G, Xiloyannis C (2010) Effects of water deficit on the vegetative response, yield and oil quality of olive trees (Olive europaea L., cv Coratina) grown under intensive cultivation. Sci Hortic 125:222-229

19. Allalout A, Krichèn D, Methenni K, Taamalli A, Oueslati I, Daoud D, Zarrouk M (2009) Characterization of virgin olive oil from Super Intensive Spanish and Greek varieties grown in northern Tunisia. Sci Hortic 120:77-83

20. Simopoulos AP, DiNicolantonio JJ (2016) The importance of a balanced $\omega-6$ to $\omega-3$ ratio in the prevention and management of obesity. Open Heart 3:e000385

21. Marongui B, Özcan MM, Rosa A, Dessi MA, Piras A, AlJuhaimi F (2015) Monitoring of the fatty acid compositions of some olive oils. Riv Ital Sostanze Grasse 92:39-42

22. Paiva-Martins F, Kiritsakis A (2017) Olive fruit and olive oil composition and their functionalcompounds. In: Kiritsakis A, Shahidi $\mathrm{F}$ (eds) Olives and olive oil as functional foods. Bioactivity, chemistry and processing. Wiley, Hoboken, pp 81-116

23. Shahzad N, Khan W, Shadab MD, Ali A, Saluja SS, Sharma S, Al-Allaf FA, Abduljaleel Z, Ibrahim IAA (2017) Phytosterols as a natural anticancer agent: current status and future perspective. Biomed Pharmacol 88:786-794
24. Covas MI, Ruiz-Gutiérrez V, de la Torre R, Kafatos A, LamuelaRaventós RM, Osada J, Owen RW, Visioli F (2006) Minor components of olive oil: evidence to date of health benefits in humans. Nutr Rev 64:S20-S30

25. Pirodi M, Albini A, Fabiani R, Giovannelli L, Luceri C, Natella F, Rosignoli P, Rossi T, Taticchi A, Servili M, Galli F (2017) Nutrigenomics of extra-virgin olive oil: a review. Biofactors 43:17-41

26. Franco MN, Galeano-Díaz T, Sánchez J, De Miguel C, MartínVertedor D (2014) Total phenolic compounds and tocopherols profiles of seven olive oil varieties grown in the South-West of Spain. J Oleo Sci 63:115-125

27. Aparicio R, Roda L, Albi MA, Gutiérrez F (1999) Effect of various compounds on virgin olive oil stability measured by Rancimat. J Agric Food Chem 47:4150-4155

28. Bullota S, Celano M, Lepore SM, Montalcini T, Pujia A, Russo D (2014) Beneficial effects of the olive oil phenolic components oleuropein and hydroxytyrosol: focus on protection against cardiovascular and metabolic diseases. J Transl Med 12:1-9

29. Krychene D, Salvador MD, Fregapane G (2015) Stability of virgin olive oil phenolic compounds during long-term storage (18 months) at temperatures of $5-50{ }^{\circ} \mathrm{C}$. J Agric Food Chem 63:6779-6786

30. Aparicio-Ruiz R, García-González DL, Oliver-Pozo C, Tena N, Morales MT, Aparicio A (2016) Phenolic profile of virgin olive oils with and without sensory defects: oils with non-oxidative defects exhibit a considerable concentration of phenols. Eur J Lipid Sci Technol 118:299-307

31. Yorulmaz A, Poyrazoğlu ES, Özcan MM, Tekin A (2012) Phenolic profiles of Turkish olives and olive oils. Eur J Lipid Sci Technol 14:1083-1093

32. Arslan A, Özcan MM (2011) Phenolic profile and antioxidant activity of olive fruits of the Turkish variety "Sarıulak" from different locations. Grasas Aceites 64:453-461

33. Dağdelen A, Tümen G, Özcan MM, Dündar E (2013) Phenolics profiles of olive fruits (Olea europaea L.) and oils from Ayvalık, Domat and Gemlik varieties at different ripening stages. Food Chem 136:41-45

34. Malheiro R, Rodrigues N, Pereira JA (2015). In: Boskou D (ed) Olive and olive oil bioactive constituents. AOCS Press, Urbana

35. Criado MN, Morelló JR, Motilva MJ, Romero MP (2004) Effect of growing area on pigment and phenolic fractions of virgin olive oils of the Arbequina variety in Spain. J Am Oil Chem Soc 81:633-640

36. Gómez-Rico A, Fregapane G, Salvador MD (2008) Effect of cultivar and ripening on minor components in Spanish olive fruits and their corresponding virgin olive oils. Food Res Int 41:433-440

37. Parkinson L, Cicerale S (2016) The health benefiting mechanisms of virgin olive oil phenolic compounds. Molecules 21:1734

38. Lerma-García MJ, Herrero-Martínez JM, Ramis-Ramos G, SimóAlfonso EF (2008) Prediction of the genetic variety of Spanish extra virgin olive oils using fatty acid and phenolic compound profiles established by direct infusion mass spectrometry. Food Chem 108:1142-1148

39. Luna G, Morales MT, Aparicio R (2006) Characterisation of 39 varietal virgin olive oils by their volatile compositions. Food Chem 98:243-252

40. Arslan A, Özcan MM (2011) Influence of growing area and harvest date on the organic acid composition of olive fruits from Gemlik variety. Sci Hortic 130:633-641 